The Journal of

Thoracic and

Cardiovascular

Surgery

Vol 124, No. 4, October 2002

\title{
Presidential address: Our heritage and our future
}

Timothy J. Gardner, MD

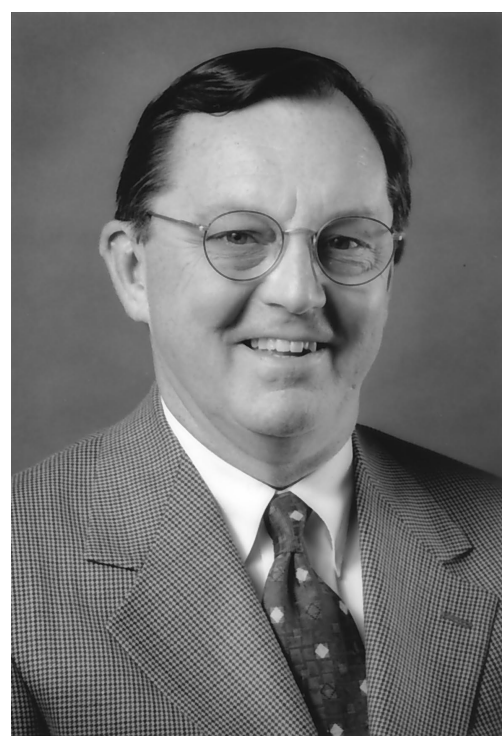

Dr Gardner

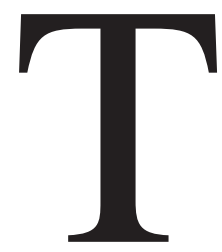

hank you, Dr Crawford, for your very kind and overly generous introduction. People who know me well recognize the exaggerations, but for the rest of you, please take everything he said as the gospel truth.

I am standing here as president of The American Association for Thoracic Surgery thanks to a lot of good fortune and, even more important, thanks to some very good people. As I remarked when I was leaving Johns Hopkins for Philadelphia, what I had become professionally at that time was about one third the result of my own efforts and two thirds a result of the Hopkins environment and my colleagues there. Whatever we have accomplished at the University of Pennsylvania has been the result of teamwork, and the team has included my superb colleagues in cardiothoracic surgery and anesthesia, a great teaching environment, and some staunch supporters. Casey Stengel said, "Managing a baseball team is getting paid for home runs someone else hits." That has certainly been my story at Penn. I am very grateful to the numerous people over the years who have nurtured and supported my efforts and especially to my current colleagues in Philadelphia. Very special thanks also go to my wife, Nina; to our 4 children, Julie, Joby, Emily, and Nick; and to my close friends for the love, support, and happiness that I have received from each of them.

Two years ago, in his excellent presidential address to this Association entitled "The Innovation Imperative," Toby Cosgrove began by stating: "For thoracic surgeons, this is the best of times and the worst of times." That was May 2000, when the United States was at the prosperous apex of a peaceful and benign international society, where goodwill and mutual respect reigned. We were in the midst of an unprecedented and sustained economic boom that, as Toby pointed out, was powering the entrepreneurial dreams of millions of people. At that same AATS meeting, we heard predictions of the anticipated effect of genetically based medicine by Craig Venter, a visionary scientist who had forced the pace of development of the human genome project by bold personal leadership and by gaining support for the project from the private sector.

Now, just 2 years later, Americans have been shaken by the horror of September 11. We have had to confront a profound hatred and accept that our society, of which we have been so confident, is not seen as benevolent and generous by many people for whom we feel no malice. Even before that searing day in September, the entrepreneurial glow had faded, and the bubble, although perhaps not burst, had, at least, become a lot smaller. Even the human genome project has been forced to confront the harsh demands that are encountered when a vision moves into the implementation stage.

Back in May 2000, what were the factors that Toby said were responsible for the worst-of-times circumstances? He cited the serious erosion of reimbursement for surgical services; increasing competition from other medical specialists, in particular from interventional cardiologists; escalating malpractice actions; and a loss of societal respect and esteem for the medical profession on the basis of a barely 
concealed suspicion that high-tech medical and surgical care are, in some way, being driven by a crass profit motive. Another commonly cited sign of our worst-of-times scenario was the pervasive belief in our medical schools, and in surgical residency programs, that thoracic surgery might no longer be attracting the best and brightest young physicians. Perhaps the worst symptoms of our professional melancholy at that time were the disheartening examples of thoracic surgeons telling their children and other young people with an interest in thoracic surgery that ours is a career to avoid.

Has our situation improved during these past 2 years while many aspects of the best-of-times scenario deteriorated? Have any of the negative factors of May 2000 been ameliorated over the last 2 years? Most of us would answer with a resounding "no" and would state that thoracic surgery's situation appears to have deteriorated further. In fact, what now might be even more demoralizing than advice from older surgeons to young people to stay out of the specialty is the difficulty thoracic surgery residents are having in finding appropriate career positions when finishing their training. After spending a decade of postgraduate training, including, in many instances, highly productive periods of research and/or extra training in areas such as congenital heart surgery, transplantation, and advanced vascular surgery, thoracic surgery residents often struggle just to find employment in professional environments for which they are overtrained.

Thoracic surgery residents are frustrated and angry. They see formerly attractive faculty positions at academic centers disappearing as the practice of cardiac surgery shifts to the community. They see older thoracic surgeons remaining surgically active for more years than had been the case even a decade ago. They look to us in national and regional thoracic surgery associations and to the Board of Thoracic Surgery, the Residency Review Commission, and the Thoracic Surgery Directors Association and wonder why we have been unable - or in their view unwilling - to make things right as they start up career ladders, access to which is blocked or limited for many of them.

Other negative influences continue to affect the specialty as well. Support for thoracic surgery services has declined further, especially for cardiac surgeons. Our specialty's efforts to enlighten members of congress about the threat to specialty care for Medicare patients might have staved off some early, draconian reimbursement reductions, but we have been distinctly unsuccessful to date in influencing in any substantive way health policy specialists and legislators by our direct political action.

Another ominous trend has been declining support for surgeon-researchers by the National Institutes of Health (NIH). In fact, the Center for Scientific Review (CSR), the $\mathrm{NIH}$ agency that runs the peer review process for research grant applications, proposed eliminating the 2 study sec- tions that review most cardiothoracic and vascular grant applications. A current proposal would send these applications to study sections and review groups comprised primarily of basic scientists and medical specialists. In justification, CSR cites declining application submissions from surgeons, as well as fewer thoracic surgeon-researchers to serve as peer reviewers. This might be a chicken versus egg argument, but wherever the true explanation lies, NIHfunded research for many cardiothoracic surgeons could be entering a death spiral, especially if the CSR is successful in eliminating surgery-oriented study sections.

Another challenge for the specialty might be a result of thoracic surgery's success on the business side of medicine. Consultants are still assuring their community-hospital clients, including those who are part of the new wave of for-profit hospital ownership companies, that any hospital with a cardiologist or 2 who can perform coronary catheterizations will become very profitable if a cardiac surgery program is established. After a brief hiatus in new surgical program starts in the United States, 2001 witnessed an 11\% increase in new open-heart programs nationally. Few states have been able to withstand the pressure to dismantle Certificate of Need regulations that were established to ensure the appropriateness of and need for new cardiac catheterization laboratories and surgical programs.

A predictable result of the dispersion of open-heart surgery programs has been the leakage of surgery activity from academic centers, which still bear the responsibility for resident training. Marginally adequate surgery training experiences are commonplace, especially in key areas, such as neonatal congenital heart surgery, esophageal surgery, offpump coronary artery bypass grafting, and limited-exposure procedures in adult cardiac surgery. Another business fact of life affecting our specialty is cardiothoracic surgery's role as a major profit center for hospitals; highly successful and lucrative surgery programs are essential for many hospitals' financial viability, including academic medical centers. Hospital CEOs want star performers on their surgical teams, surgeons who sometimes are marketed like marquee idols in the hard-hitting competitive hospital and cardiovascular program environment. Although there is nothing wrong with publicly acknowledging our most accomplished colleagues or even promoting our services and successes, being forced to compete in a commercial environment can make team-oriented initiatives difficult to achieve and might devalue those programs that are so conigured. This necessary bottom-line orientation also might diminish surgerytraining priorities. Norman Shumway is quoted as saying: "The only hard thing about cardiac surgery is getting to do cardiac surgery." This aphorism apparently resulted from his experience as a trainee at the University of Minnesota under C. Walton Lillehei at a time of such pioneering heart procedures that surgery residents rarely got anywhere near 
the operating table. Some of our residents today find themselves at a similar disadvantage.

But does all of this professional angst really make this the worst of times for thoracic surgery? Are we facing new challenges that we have not seen before, or have these demands been experienced previously but in different guises? First off, let us acknowledge that some current aspects of the specialty are fine. For the general thoracic surgeon, this has been a generally favorable period. Chest surgery has evolved over the past 40 years from being dominated by difficult salvage procedures on patients with tuberculosis and other inflammatory diseases to a highly productive era of thoracic surgical oncology that continues to advance today and will for the foreseeable future. Lung transplantation and other novel surgical procedures for degenerative pulmonary conditions, including congenital and genetic diseases, have general thoracic surgeons expressing positive sentiments about the future of this subspecialty. At the recent General Thoracic Surgery Club meeting, referred to by many of its members as their best professional meeting of the year, they discussed new technologies available for lung surgery, such as tissue sealants and cyber knife use. They also discussed new approaches for lung cancer treatment, including gene therapy, angiogenesis, and retinoids. The field is on solid clinical footing, and trainees find plenty of career opportunities in a variety of general thoracic surgery settings of their choice. Sustained advances in thoracic oncology and in other areas, such as airway reconstruction and surgical treatment of obstructive lung disease, are expected. Minimally invasive videoscopic thoracic surgery has been embraced and mastered, and the future seems to be bright, indeed.

Even for the general thoracic surgeon, however, our specialty is being seriously threatened. The worsening challenge of maintaining appropriate financial support for surgeons and for the effective but expensive services that we provide is being experienced in similar ways throughout the developed world, regardless of the nature of the various national health care systems. Governments have assumed the responsibility of ensuring, and in most instances insuring, health care for its citizens. The United States claims to have a free-enterprise medical system, but this is only partially so. Clearly the overly regulated Medicare program is the major force in health care coverage in this country. Floyd Loop, in his presidential address to the AATS in 1998, commented that, "Washington is trying to establish universal health care through regulations. . . . Congress affects the legislative and regulatory requirements often unwittingly, because the members are uninformed. The legal profession [which dominates the legislative branch of government] may strengthen society, but writing regulations that affect science and medicine has not been one of their distinguished contributions. Few members of any con- gressional committee have enough background in technology, medicine, or science to legislate in this area, nor are they interested in acquiring such knowledge." Those of us who have attempted to engage members of congress or even their staff and aides know how accurate Dr Loop's observation is. When we attempt to inform the legislative process, we are politely received, but the attention spans are short, and levels of interest are minimal. Dr Loop predicted in 1998 what has continued to unfold since then: "Once they have squeezed physician reimbursement, the [government] regulators will turn to suppressing medical advancements at a time when we have an aging population."

How can thoracic surgeons have an effect on our various national health care programs? We must promote and nurture health policy expertise within the specialty. Virtually all active and respected participants of the health policy community in North America and Europe are primary care physicians. The Harvard Kennedy School Health Policy course, conceived by Jack Matloff and supported by the Thoracic Surgery Foundation for Research and Education, has provided a good beginning for some of our colleagues. Also, we must be willing to encourage and support those few surgeons and other physicians familiar with the contemporary challenges of specialty medicine who choose government service and especially those willing to assume the burden of elective office. In Washington, as in most national and regional governments, health policy, although molded by policy gurus and managed by bureaucrats, is transformed into action by elected or politically appointed individuals. When a surgeon becomes a player in this latter group in the US Federal Government, there can be some rebalancing of this serious design flaw of our current legislative and executive government model. Physicians, surgeons, scientists, and technology experts are not sufficiently engaged in government activities. Again, to quote $\mathrm{Dr}$ Loop's presidential comments, "In a technologically based society, this legislative climate of ignorance is inexcusable and potentially fatal." There is a thoracic surgeon in the US Senate, but many of us are disappointed that Senator Frist has not turned around Medicare physician reimbursement. Many seem to consider him personally responsible for continued physician payment declines. The significance of his participation in the US Senate, as with the participation and leadership of the few other medical specialists in the House of Representatives, in the executive agencies of government, and at the NIH, Food and Drug Administration, and Institute of Medicine, cannot be overemphasized. There is another surgeon, Representative Greg Ganske from Iowa, who is a Harvard-trained plastic surgeon, running this year for the US Senate. We need to support these individuals, even if the nuances of their political party or philosophy do not correspond entirely or exactly with our own. Having surgeons and other physicians who understand our profes- 
sional goals and challenges is decidedly more important, I believe, than being in complete social or political concordance with a physician-legislator.

As important as greater political and societal engagement is for the future of the specialty, a much more fundamental concern is causing widespread apprehension among us today. Many believe that the golden era of thoracic surgery, or at least that of cardiac surgery, has passed and that the future of the specialty is limited and uncertain. Our clinical challenges have intensified, our support and rewards have diminished, our young colleagues are discouraged, and prospective candidates for the specialty appear to be declining. But again, let me pose the question: Are we facing new challenges that we have not encountered previously, or are we coping with challenges experienced before under different guises? Let us look at some aspects of our specialty's history and see what insights into our present dilemmas we might be able to achieve.

I personally was exposed, directly or tangentially, to a few of the early and exciting developments in cardiac surgery. My first mentor in medicine was Proctor Harvey, a protégée of Paul Dudley White at Harvard, who was head of cardiology at Georgetown here when Nina and I were medical students. I assumed that I would be a cardiologist until I saw Dr Charles Hufnagel in action-a true surgical pioneer who, among other firsts in surgery, implanted a ball valve in a patient's descending aorta in the early 1950s to treat severe aortic regurgitation. Dr Hufnagel's long and exciting days in the operating room, followed by real teaching rounds until late in the evening, inspired me. Also, he directed a research laboratory at Georgetown, where he developed and studied a variety of mechanical prostheses and techniques for valve replacement. I made a leap of faith and applied for a surgery internship. After medical school, Nina and I moved the short distance to Johns Hopkins for our subsequent training. We arrived there the year after Dr Blalock's death. The hallway in the Department of Surgery at Hopkins was lined, as is the case at many academic centers, with pictures of the program's former residents. There had been a generation of thoracic surgeons at Johns Hopkins who participated in the formative growth and early accomplishments of cardiac surgery. Many of these same Blalock-trained residents help lead this specialty, and this Association, through the next decades of mind-boggling expansion into the treatment of coronary artery disease, aortic disease, transplantation, and neonatal surgery.

Vincent Gott, who had trained in surgery along with Dr Shumway under Dr Lillehei and his associates at Minnesota and then continued his own medical device research at the University of Wisconsin and Hopkins, was my mentor and surgical teacher at Hopkins, along with many other superb surgeons and fellow residents. It was a somewhat unique and idealistic environment, based solidly on a robust and dedicated surgical tradition. David Skinner was a member of the Hopkins Surgery Faculty at the same time when Mark Orringer and I were residents together.

My training at Hopkins culminated with an all-too-brief stint as registrar with Sir Brian Barratt-Boyes and his outstanding team at Green Lane Hospital in Auckland. Sir Brian is another master surgeon who, at that time, was pushing back seemingly insurmountable obstacles and making corrective infant heart surgery possible. As I watched a truly brilliant surgeon for a relatively short time, I seemed to be absorbing years of surgical training, experience, and a mind set that has served me well.

I experienced another important influence in 1982, when the cardiac surgery group at Hopkins was joined by Bruce Reitz and Bill Baumgartner from Stanford. Some surgeons speak of their thoracic surgery heritage in ways reminiscent of how a philosopher or artist might be identified with a particular school of thought or artistic style. We even have some surgeons referring to themselves as second- or thirdgeneration DeBakey or Sabiston or Churchill or Kirklin trainees. I feel like a Shumway trainee, once or twice removed, on the basis of the tremendous influence that Bruce Reitz had on my own practice of cardiac surgery. I hope that we returned the favor to Dr Shumway through one of our own favorite surgery residents.

Thoracic surgeons have been accused of practicing elder worship, and if one reviews the presidential addresses to this Association, you can find ample evidence of this propensity. But we should look at our thoracic surgery heritage to redefine our goals and to invigorate our spirits in what remains a very demanding but innovative surgical specialty, where the sky continues to be the limit in multiple dimensions. Robert Wallace, in his presidential address to this Association in 1995, told the story of having met a very senior surgeon on his first day as a surgery intern. The surgeon offered his sympathy, assuring Bob that surgery had had its day and that he was embarking on a dead-end career. Many of us are saying the same thing to our students, residents, and young associates today, making the same depressing and misguided error that Bob's senior surgeon made. We must focus on our heritage, its lessons, and its inspirations and see what that history teaches us, not just about the here and now but also about our future.

Who could possibly have imagined what would happen in less than 50 years after Dr Blalock treated that first blue child with a simple but at that time extremely challenging operation? Not only was the operation itself an amazing accomplishment, but the manner in which that particular operation evolved should be a lesson for us. Dr Blalock was a surgeon-researcher at Vanderbilt before being appointed Surgeon-in-Chief at Hopkins. While at Vanderbilt, he attempted to create an animal model of pulmonary hypertension by constructing subclavian-to-pulmonary artery con- 
nections. With that experience, he was serendipitously prepared to respond to Helen Taussig's distress when she lamented the underlying physiologic problem of inadequate pulmonary blood flow in children with tetralogy of Fallot. It is unlikely that a subclavian-pulmonary artery connection would have been tried, let alone been imagined, without his experience in the Vanderbilt research laboratory. Nor would it have happened without his collaborative relationship with Dr Taussig in an environment such as exists at Johns Hopkins.

A few years later, at a time when many very smart and wise physicians were absolutely certain that a heart-lung bypass machine would never function or function safely, Dr Lillehei forged ahead with a technique for repairing the heart that would never pass institutional review board muster today-parental cross-circulation. When crude but functional cardiopulmonary bypass pumps became barely operational, a group of brave surgeons operating on desperate but hopeful patients forced the medical community to acknowledge the promise of cardiothoracic surgery.

The entire history of thoracic surgery is characterized by such vision and by a determined willingness to take risks with the expectation of progress. This is not a specialty that has achieved what has been experienced over the last 60 years in cardiac surgery and over the last 80 years in chest surgery by accepting the therapeutic status quo. We hear thoracic surgeons speak of our specialty as being mature. If mature in this context is meant to indicate established or experienced, all right. But if mature is intended to connote fulfillment, a flattening out or a loss of momentum and progress, then these individuals are very wrong. They might have reached their own peaks and their own personal bests, but I am certain that the specialty is nowhere near achieving and fulfilling its ultimate potential for the benefit of patients with thoracic and cardiac disease.

How can I say that the future of our specialty is favorable, let alone bright and positive, at a time of apparent declining cardiothoracic surgery activity, along with the palpable demoralization and generalized ennui of so many thoracic surgeons? How can we justify encouraging students and residents to enter this specialty? And even more germane to present circumstances, how can we defend having our trainees or young faculty work in basic science laboratories or pursue $\mathrm{PhDs}$ or spend time at places like Harvard's Kennedy School of Government or submit research applications to the Agency for Health Quality Research? I believe passionately in 2 basic principles of human enterprise that have been firmly established by repeated lessons of our history: progress is inevitable, and challenges are overcome, either creatively or by adaptation and evolution. I am not foolish enough to try to predict when progress and what specific improvements will be achieved, but I am confident enough in our collective heritage and experience to know that we will prosper, that our specialty will continue to evolve, and that our potential for achieving unimagined progress as thoracic surgeons is quite unlimited. Aldous Huxley said the following in an essay titled The Case of Voluntary Ignorance: "(The fact) that men do not learn very much from the lessons of history is the most important of all the lessons that history has to teach."

Eighty years ago, surgery of the lung and chest was nearly impossible. Fifty years ago, direct surgery on and in the heart was a pipe dream. Those surgeons who pushed thoracic surgery into reality, some of whom are here with us today, were considered fools or even charlatans for promoting high-risk surgery for patients with miserable and essentially untreatable conditions, such as tuberculosis, lung cancer, congenital heart disease, rheumatic fever, esophageal obstruction, and ischemic heart disease. The incredible progress that has characterized the specialty over this period has been the result of individual medical leadership, boldness, risk taking, imagination, basic and translational research, sustained hard work and dedication, and a very special and unique mentoring environment within the specialty.

With this heritage and culture, why should we fear the future? Are we and those coming behind us any less talented or committed than those surgeons of 20 or 40 or 60 years ago? Are the scientific, societal, ethical, and even financial challenges of today orders of magnitude worse than these same factors were 50 years ago? In fact, an accurate historical analysis of the earlier days of thoracic surgery will dispel this commonly held opinion. In certain respects, our challenges to continued exponential progress in thoracic surgery today and in the immediate future pale in comparison with those of 50, 40, or even 30 years ago.

So just where are we now? Is this really the worst of times? Well, for this meeting of the Association, compared with the first AATS meeting that I attended 30 years ago in Atlanta, we received nearly 700 abstract submissions, the greatest number ever and a 30\% increase over 3 years. At this meeting, compared with Atlanta 30 years ago, we have nearly quadrupled the number of presentations. Attendance continues to grow. The first clinical experience with a totally implantable biventricular artificial heart has just been presented, as was a maturing and promising experience with beating heart coronary surgery. Forum presentations and Lillehei resident presentations, many reporting on sophisticated basic science studies, continue to be numerous and of excellent quality. Over $35 \%$ of the presentations at this meeting are from outside North America, giving ample testament not just to the international breadth of our specialty's strengths but also to the global collaborative nature of thoracic surgery. We now have at least 3 major international thoracic surgery meetings annually, including the European Association for Cardio-thoracic Surgery, and we 
have developed a truly international thoracic surgery society with CTSNet, the Cardiothoracic Surgery electronic community of over 18,000 thoracic surgeons.

What must we do to ensure our specialty's future? Clearly our core mission is the accomplishment of excellent surgical care. Our residency programs must insure the best possible training experiences and the best possible mentoring. Marginal training experiences must be eliminated, and inadequately prepared or inept individuals cannot be allowed to practice as certified thoracic surgeons. Our ability to monitor our clinical effectiveness and promote quality improvement are unsurpassed today with instruments like the Society for Thoracic Surgeons database programs, and we must insist on compliance with contemporary qualityassurance measures. If we are unable to provide highquality surgical care to our patients, we are worthless to society.

We must also be driven by a compulsion for progress and innovation. The fundamental and defining research tradition that has resulted in so much progress in this specialty must be vigorously supported, with the scope of the research and development encompassing not just basic biologic research but also fields including informatics and communications, process improvement, outcomes analysis, education, and competency assessment. In the traditional research areas, we should continue to promote and invest heavily in translational research, an area in which we are uniquely qualified. Dr Elias Zerhouni, the recently nominated director of the NIH, predicted that this will be the biomedical century, following what others at NIH referred to as the molecular era. These research pursuits are not mutually exclusive, as many in the basic science community fear. We can hope that surgery, bioengineering, and imaging research will experience a renaissance of attention and support with Dr Zerhouni's broader view of the NIH's mission.

Please do not misinterpret my message as ravings or the wishful thinking of someone still sporting a suntan from our golden era. I am absolutely certain that those coming along behind this mature generation of thoracic surgeons will surpass our accomplishments. One commonly claimed indicator of the impending decline of US thoracic surgery is the emergence of the "foreign medical graduate" in thoracic residency programs, coincident with the alleged fleeing of the best and brightest from training slots in our specialty. Although some residents and trainees educated abroad do struggle with cultural assimilation as they attempt and are expected to function flawlessly in our demanding programs, the future accomplishments of medicine, science, and technology in the United States will be greatly determined by the work and productivity of first- and second-generation new Americans. This country is a nation of immigrantsthe United States is what we have become today because of the waves of newcomers, eager for opportunities for per- sonal and societal improvement. Just as this current American generation has prospered from the participation and influence of descendants of immigrants from central and Eastern Europe, this next generation of Americans will be enriched by Hispanic Americans and by the many brilliant and hard-working young Asian Americans who we are most fortunate to have within our ranks.

The American Association of Thoracic Surgery is our direct link to the awesome heritage of this specialty of thoracic surgery. For years, its members were practitioners of lung and chest wall surgery only. Just as we have evolved over the past 50 years to encompass cardiac, esophageal, neonatal, and airway surgery, the Association will confront our emerging challenges and help lead our specialty as it evolves in ways that we can only speculate about at this point. Our past president, Jim Cox, last year challenged us to turn some of our attention to those parts of the world where the benefits of thoracic surgery are yet to be experienced. Our next president, Fred Crawford, is personally committed to ensuring that thoracic surgery education and training evolve most appropriately in a rapidly changing environment. At the most recent Association Council meeting, we established a Research Advisory Committee to be led by Pedro del Nido, Alec Patterson, Craig Miller, and other accomplished surgeon-researchers, whose charge it is to keep the Association and the specialty focused on our essential research and development mission. We enthusiastically embrace and support CTSNet's vision for a global cardiothoracic community, and we will continue to work collaboratively with the Society of Thoracic Surgeons, with our other regional professional societies, and with the European Association for Cardio-thoracic Surgery.

To our young colleagues, I would like to emphasize that the future is yours for the taking. If there is not the precise opportunity that you envisioned for yourself, make it happen at the next best place. The sine qua non for success is unequivocal surgical competence, but how else you define yourself professionally and personally is limitless. Be well informed and be personally involved with the public and with health policy activities. Support research and innovation, either through direct participation or by supporting your colleagues who do pursue research and development activities. Also, in whatever your professional setting, mentor and educate those working with you and those following you in the specialty.

I thank the Association for the great honor of serving as president. There are many others more deserving of this honor, but I am very grateful to have had the opportunity to join the distinguished line of thoracic surgeons who have made this Association a beacon of our aspirations and expectations for the future of thoracic surgery on the basis of the incredible accomplishments of those surgeons who have preceded us. Thank you. 